\title{
INSTITUTIONAL STUDY OF PRIMARY CAESAREAN SECTION AMONG MULTIGRAVIDA
}

\author{
A. Shanti Sri ${ }^{1}$, Anjum Kekhashan² \\ ${ }^{1}$ Associate Professor, Department of Obstetrics and Gynaecology, Princess Esra Hospital, Deccan College of Medical Sciences. \\ ${ }^{2}$ Assistant Professor, Department of Obstetrics and Gynaecology, Princess Esra Hospital, Deccan College of Medical Sciences.
}

\section{ABSTRACT}

\section{BACKGROUND}

It is a study of the analysis of cases where Caesarean section was done for the first time in a women who had previous vaginal delivery of a viable neonate. The various indications for Caesarean section, incidence, indications and maternal and foetal outcomes were studied.

\section{MATERIALS AND METHODS}

It is a prospective study of over 230 cases of Caesarean section done for the first time in a parous women admitted at Princess Esra Hospital, Deccan College of Medical Sciences, Hyderabad, over a period of one year from 1st April 2014 to 31 st March 2015. Detailed history of the present pregnancy, past obstetric history, associated comorbidities were noted. After clinical examination, labour was monitored throughout and indication for Caesarean section was noted. Intraoperative details, maternal and foetal outcomes were recorded.

\section{RESULTS}

Among the various indications for primary Caesarean section in a multiparous women presumed foetal compromise and antepartum haemorrhage were the main indications. Emergency Caesarean sections were done in majority of the patients. Spinal anaesthesia was the major type of anaesthesia employed. Atonic PPH was the commonest intraoperative complication.

\section{CONCLUSION}

Many unforeseen complications may arise in a woman who previously had a normal vaginal delivery. A previous normal delivery, though an optimistic historic fact does not always ensure a normal vaginal delivery of the pregnancy at hand.

\section{KEYWORDS}

Multipara, Primipara, Caesarean Section, Cephalopelvic Disproportion.

HOW TO CITE THIS ARTICLE: Sri AS, Kekhashan A. Institutional study of primary caesarean section among multigravida. J. Evolution Med. Dent. Sci. 2016;5(83):6157-6160, DOI: 10.14260/jemds/2016/1392

\section{BACKGROUND}

Pregnancy is not merely a woman plus a foetus and placenta, but it is a state sui generis, physiological indeed for the race, but bordering on the pathological for the mother and most hazardous for the foetus. Caesarean delivery is one of the most commonly performed operations today. Caesarean births have become safer. This is not to imply that they have become safer than normal uncomplicated vaginal deliveries, but have become safer than they used to be. Delivery by caesarean section is most frequently performed in nulliparous for dystocia with suspected cephalopelvic disproportion. Multipara means those who had delivered once or more after the age of viability. It includes primipara (Unipara - para 1) multipara (para 2, 3, 4) and grand multipara (para more than 4). In his 1934 article, entitled 'The dangerous multiparae,' Bethel Solomons wrote: "my main object is to remove if possible once and for all the idea that a primigravida means a difficult labour, but a multiparae means an easy one. It is

Financial or Other, Competing Interest: None.

Submission 27-09-2016, Peer Review 09-10-2016,

Acceptance 11-10-2016, Published 14-10-2016.

Corresponding Author:

Dr. A. Shanti Sri,

\#3-4-771/401,

Thakur Residence,

Barkatpura, Hyderabad-500027.

E-mail: shantisrinivas@gmail.com

DOI: $10.14260 /$ jemds/2016/1392 altogether a mistake to suppose that in childbearing, practice makes perfect. ${ }^{\prime \prime}$ Intrapartum complications such as foetal malpresentation, placental abruption, dysfunctional labour and postpartum haemorrhage are commonly linked to multiparity. Multiparity places the women in high risk group because of many factors, important of which are constitutional and socioeconomic. With advancing age the patient's cardiovascular system is consequently less resilient, so that hypertensive disease is more manifested. Other general conditions which are a part of the normal process of ageing are liable likewise to intrude themselves upon the clinical picture. Socioeconomic factors play a very important role, for the majority of these cases are poor, over worked and tired. Poverty deprives them from adequate nutrition, which becomes worse when they have to feed their numerous children. Obstructed labour in grand multipara is due to secondary contracted pelvis and undisguised malpresentation. The major causes of maternal morbidity among these women were ruptured uterus, hypertensive vascular disease, placenta previa and malpresentations. ${ }^{2}$ Primary caesarean section in the multipara means first caesarean section done in the patients who had delivered vaginally once or more. Mainly, the baby and the placenta are responsible for caesarean section in multipara. Multipara may still have cephalopelvic disproportion even having previously delivered a full-term child vaginally. 


\section{AIMS OF THE STUDY}

1. To study the incidence of primary caesarean section in a multipara.

2. To study the maternal and foetal morbidity and mortality following surgery.

3. To study the immediate postoperative period.

\section{MATERIALS AND METHODS}

\section{Study Design}

It was a prospective study of 230 cases of primary caesarean section in a multigravida, who had a previous vaginal delivery of a viable neonate at Princess Esra Hospital, Deccan College of Medical Sciences, Hyderabad, for a period of one year.

\section{Inclusion Criteria}

1. Multipara.

2. Term pregnancy.

3. Singleton pregnancy.

\section{Exclusion Criteria}

1. Primigravida.

2. Previous caesarean section.

3. Twin gestation.

4. Previous uterine surgery.

5. < 37 weeks.

6. No associated medical disorders.

\section{METHODOLOGY}

This study has been done in multiparous patients admitted to the hospital and were followed till discharge, which included patients admitted to the labour ward in various stages of labour and also those who were admitted in the wards for elective caesarean section. Among the patients admitted in various stages of labour, some were subjected to trial of labour and then operated upon and some were taken up for abdominal delivery straight away. All the patients taken up for the study were followed till discharge. At the time of discharge, the patients were counselled regarding the importance of spacing, contraception, immunisation of the neonate and mandatory hospital delivery in the next pregnancy.

\section{RESULTS}

\begin{tabular}{|c|c|c|}
\hline & $\begin{array}{c}\text { Number of } \\
\text { Cases }\end{array}$ & Percentage \\
\hline $\begin{array}{c}\text { Primary CS in } \\
\text { multipara }\end{array}$ & 230 & $27.38 \%$ \\
\hline CS in nullipara & 286 & $34.04 \%$ \\
\hline Total No. of Repeat CS & 324 & $38.57 \%$ \\
\hline
\end{tabular}

It was observed that total number of cases of primary C.S. in multipara $230(27.38 \%)$, total number of cases of primary C.S. in nullipara was $286(34.04 \%)$ and the total number of repeat C.S. was 324 (38.57\%).

\begin{tabular}{|c|c|c|c|}
\hline & Indication & $\begin{array}{c}\text { No. of } \\
\text { Cases }\end{array}$ & Percentage \\
\hline 1 & $\begin{array}{c}\text { Presumed Foetal } \\
\text { Compromise }\end{array}$ & 58 & $25.21 \%$ \\
\hline 2 & APH & 52 & $22.6 \%$ \\
\hline 3 & Malpresentations & 33 & $14.34 \%$ \\
\hline 4 & CPD & 36 & $15.65 \%$ \\
\hline 5 & PROM & 14 & $6.08 \%$ \\
\hline 6 & Prolonged Labour & 9 & $3.91 \%$ \\
\hline
\end{tabular}

\begin{tabular}{|c|c|c|c|}
\hline 7 & Cord Prolapsed & 5 & $2.17 \%$ \\
\hline 8 & Obstructed Labour & 6 & $2.65 \%$ \\
\hline 9 & Maternal Request & 15 & $6.52 \%$ \\
\hline 10 & Threatened Rupture & 2 & $0.86 \%$ \\
\hline \multicolumn{2}{|c|}{ Table 2: Indications for Caesarean Section in Multipara } \\
\hline
\end{tabular}

There were different indications for caesarean section in these patients. Presumed foetal compromise was the most common followed by APH; 15 of the patients in the study group requested for abdominal delivery with concomitant sterilisation expressing their inability to take the stress of labour.

\begin{tabular}{|c|c|c|}
\hline & No. of Cases & Percentage \\
\hline Booked & 190 & $82.6 \%$ \\
\hline Unbooked & 40 & $17.39 \%$ \\
\hline \multicolumn{2}{|c|}{ Table 3: Booked or Unbooked Cases } \\
\hline
\end{tabular}

In our study, 40 cases were unbooked reflecting the inadequacy of antenatal care.

\begin{tabular}{|c|c|c|}
\hline & No. of Cases & Percentage \\
\hline Emergency & 184 & $80 \%$ \\
\hline Elective & 46 & $20 \%$ \\
\hline \multicolumn{3}{|c|}{ Table 4: Timing of Surgery } \\
\hline
\end{tabular}

In $80 \%$ of the women section was done when they were in labour; 46 women were posted for an elective caesarean section, the commonest indication being breech presentation.

\begin{tabular}{|c|c|c|}
\hline & No. of Cases & Percentage \\
\hline Regional & 206 & $89.56 \%$ \\
\hline General & 24 & $10.43 \%$ \\
\hline \multicolumn{3}{|c|}{ Table 5: Type of Anaesthesia } \\
\hline
\end{tabular}

Spinal anaesthesia was the commonest accounting for $89.56 \%$. General anaesthesia was used in $10.43 \%$ of cases, common indication being abruptio placenta.

\begin{tabular}{|c|c|c|}
\hline & No. of Cases & Percentage \\
\hline Atonic & 9 & $3.91 \%$ \\
\hline Traumatic & 2 & $0.86 \%$ \\
\hline \multicolumn{2}{|c|}{ Table 6: Major Intraoperative Complications } \\
\hline
\end{tabular}

Atonic PPH was commonly seen in patients with antepartum haemorrhage. Traumatic PPH was seen in patients with obstructed labour with angle extensions.

\begin{tabular}{|c|c|c|}
\hline Maternal Morbidity & No. of Cases & Percentage \\
\hline Febrile Morbidity & 7 & $3.04 \%$ \\
\hline Abdominal Distension & 3 & $1.3 \%$ \\
\hline PPH & 11 & $4.78 \%$ \\
\hline RTI & 4 & $1.73 \%$ \\
\hline Wound Infection & 6 & $2.6 \%$ \\
\hline \multicolumn{2}{|c|}{ Table 7: Causes of Maternal Morbidity } \\
\hline
\end{tabular}

In this study, 28 patients had morbidity after caesarean section giving an incidence of $12.17 \%$. PPH and febrile morbidity were common followed by wound sepsis.

\section{Maternal Mortality}

There were no cases of maternal mortality in the present study. Although, caesarean section has a mortality rate $<1 \%$, in many developing countries it is 10-20 times greater with caesarean section compared to vaginal delivery. ${ }^{3}$ No 
significant difference in maternal mortality was found between elective caesarean delivery and planned vaginal delivery. 4,5

\begin{tabular}{|c|c|c|}
\hline & No. of Cases & Percentage \\
\hline TTNB & 18 & $7.82 \%$ \\
\hline Hypoglycaemia & 6 & $2.6 \%$ \\
\hline MSAF & 4 & $1.73 \%$ \\
\hline Sepsis & 18 & $7.82 \%$ \\
\hline RDS & 12 & $5.21 \%$ \\
\hline Anomalies & 4 & $1.73 \%$ \\
\hline \multicolumn{2}{|c|}{ Table 8: Perinatal Morbidity } \\
\hline
\end{tabular}

62 babies had perinatal morbidity requiring NICU admission. TTNB was the commonest cause. There were 2 stillbirths, cause being abruption in both the cases.

\section{DISCUSSION}

Multiparity is a problem associated with poverty, illiteracy, ignorance and lack of knowledge of the available antenatal care and family planning methods. A multipara who has earlier delivered vaginally may still require a caesarean section for safe delivery. The relative ease with which some multiparous are delivered in the presence of faulty positions may account for the false sense of security. ${ }^{6}$ In this study primary caesarean sections in multipara constitute small percentage of total deliveries (27.38\%), which is quite less than primary caesarean in nullipara, but they are actually associated with high maternal and foetal morbidity. In summary, global increase in caesarean section rates may be due to combination of factors: increased safety of procedure, increased use of foetal monitoring and medicolegal situations and fear of malpractice suits, ${ }^{7}$ obstetric indications, ${ }^{8}$ maternal request.9,10,11 This study reemphasises the need of thorough antenatal care and vigilance in the management of labour, negligence in which most of the time needs operative interventions for the good concerns of both the mother and the baby. Above this there is a great need to counsel multipara to report to the hospital as early as possible, as many of them are likely to try a home delivery and on failing which they come down to the hospital. Foetal Distress (25.21\%), APH (22.09\%), CPD (15.65\%) and abnormal presentations (14.34\%) were the most common indications for caesarean sections. Most common indication in the study by Jyothi and Nirmala and Jacob and Bhargava, were malpresentations and antepartum hoemorrhage.12,13 In another study, antepartum or intrapartum foetal distress was leading indication in 41 percent of women, failure to progress being second cause. ${ }^{14}$ Presumed foetal compromise in our study was $25.21 \%$. The electronic foetal monitoring, which is commonly used to detect foetal distress is known to have poor specificity resulting in increased number of caesarean sections carried out for foetal distress. ${ }^{14}$ Fear of litigation increases the use of continuous foetal monitoring and intervention early in labour. Mortality rate at tertiary care hospitals is less because of good antepartum and intrapartum care. Unrecognised cephalopelvic disproportion leading to obstructed labour (in referred cases) is a contributing factor in increasing maternal morbidity. Hence, a multipara woman in labour requires the same attention as that of a primigravida. Good antenatal and intrapartum care and early referral can reduce the maternal and perinatal morbidity and mortality in a multipara.

\section{CONCLUSIONS}

From the above study, it is very clear that many unforeseen complications occur in women who had not previously had a normal vaginal delivery. Multiparity in our society is not by choice; this results in a high birth rate and so many young women become grand multipara. This process causes short birth intervals, eventually jeopardising the health of the mother and her offspring. This study reemphasises the need of antenatal care and thorough care and vigilance in the management of labour. Though vaginal delivery is always safer than C-section, difficult vaginal delivery and obstructed labour carries more morbidity and perinatal mortality when compared to elective $\mathrm{C}$-section. Previous vaginal delivery gives the patient as well as her relatives a false sense of security. In many cases, a caesarean section becomes mandatory. The fact that a multipara has had one or more vaginal deliveries should be regarded as an optimistic historical fact, not as a diagnostic criteria for spontaneous. The concept that multiparous patients rarely have foetopelvic disproportion has resulted in undue delay in performing caesarean section. A multigravida in labour with an unengaged presenting part should receive the same careful investigation as the primigravida. Today, caesarean section is the most commonly performed obstetric surgery. With the advent of higher antibiotics availability of blood transfusion facilities, anaesthetist skills, better surgical technique have all made a caesarean section more safer than before. Therefore, early recognition of complications, timely intervention will decrease foetal loss and also improve foetal outcome. Multiparity is still an obstetrical challenge, because of numerous hazards related to pregnancy and labour. Therefore, they require the utmost care in their management. They should be explained the need for attending antenatal clinic and the family planning clinic. They should be convinced regarding adoption of sterilisation to limit their family planning and thereby avoid disastrous effects of high parity. Caesarean section should be done only when there is medical indication. ${ }^{15}$

\section{REFERENCES}

1. Solomon B. The dangerous multipara. Lancet 1932;2: 8-11.

2. Eastman N. Multiparity and its effect on maternal and perinatal mortality. Obstet Gynecol Surv 1958;13:833-7.

3. Baldo MH. Caesarean section in countries of eastern mediterranean region. La Revue de Sante de la Mediterranee orientale 2008;14(2):470-88.

4. Carbonne B. Increase in caesarean delivery: are we facing a pandemic? International Journal of Gynecology and Obstetrics 2009;107(3):183-4.

5. Liu S, Liston RM, Joseph KS, et al. Maternal mortality and severe morbidity associated with low-risk planned cesarean delivery versus planned vaginal delivery at term. CMAJ 2007;176(4):455-60.

6. Basak S, Lahiri D. Dystocia in eutocic multigravida. J Obstet \& Gynec 1975;25:502-7.

7. Declercq E, Menacker F, Macdorman M. Maternal risk profiles and the primary cesarean rate in the United States, 1991-2002. American Journal of Public Health 2006;96(5):867-72.

8. Shehata AI, Hashim TJ. Decrease in perinatal mortality and increase in caesarean section rates. International Journal of Gynecology \& Obstetrics 1995;48:261-7. 
9. Chigbu CO, Ezeome IV, Ilobachie GC. Cesarean section on request in a developing country. International Journal of Gynecology and Obstetrics 2007;96(1):54-6.

10. Menacker F, Declercq E, Macdorman MF. Cesarean delivery: background, trends, and epidemology. Semin Perinatol 2006;30(5):235-41.

11. Mukherjee SN. Rising cesarean section rate. J Obstet Gynecol India 2006;56(4):298-300.

12. Jacob S, Bhargava H. Primary caesarean in multipara. J Obstet \& Gynec India 1972;22(6):642-50.
13. Rao JH, Rampure N. Study of primary caesarean section in multiparous women. Journal of Evolution of Medical and Dental Sciences 2013;2(24):4414-8.

14. Goonewardene M, Manawadu MH, Priyaranjana DV. Audit: the strategy to reduce the rising caesarean section rates. J South Asian Feder Obst Gynae 2012;4(1):5-9.

15. Lumbiganon $\mathrm{P}$, Laopaiboon $\mathrm{M}$, Gulmezoglu $\mathrm{AM}$, et al. Method of delivery and pregnancy outcomes in Asia: the WHO global survey on maternal and perinatal health 2007-08. Lancet 2010;375(9713):490-9. 